\title{
Relationship between Sexual Behaviour/Habits and Occurrence of Lowback Pain among Metal Workers in a South-Eastern Nigeria Community
}

\author{
Article by Gabriel O. Ayeni ${ }^{1}$, Okwuoma C Abanobi ${ }^{2}$, Oluwasegun A. Ayeni ${ }^{3}$. \\ ${ }^{1}$ Physiotherapy Department, Federal Medical Centre, Owerri, Imo State, Nigeria \\ ${ }^{2}$ Public Health Department, Federal University of Technology, Owerri, Imo State, \\ Nigeria \\ ${ }^{3}$ Mathematics/Statistic Department, University of Ibadan, Ibadan, Oyo State, Nigeria \\ Corresponding author: \\ Email:ayenco2@yahoo.com
}

\begin{abstract}
Objective:

Low back pain (LBP) incidence among metal workers is relatively high. This study assessed the sexual habits relationship to LBP among metal workers in Owerri, South-eastern Nigeria.

Study design

A prospective cases-control study design

Methods:

A surveillance exercise was carried out. A simple random sampling was used to select 50 cases and matched to 50 non-cases from identified cases and noncases. Frequency matching was done. Data analysis was carried out using descriptive and inferential statistics of $2 \times 2$ contingency table.

Results:

Sexual habits such as having multiple sex partners $(O R=0.26, C I=0.35-1.25 ; p<$ $0.04)$, higher sex frequency $(O R=0.73, C I=0.16-3.46 ; p<0.05)$, married $(O R=1.00$, $C I=0.446-2.242, p>0.58)$ were not significantly associated with LBP.

Conclusion:

There was no association between higher sex frequency per week, having multiple sex partners or not, married or not married and occurrence of lowback pain. However, the need for further study to determine how well metal workers manage their sexual life and their health was stated, as all sampled metal workers engaged in sexual activities irrespective of their marital status.
\end{abstract}

Key words: Low back pain, metal workers, welders, panel beaters, sexual behaviour, sexual habits.

\section{Introduction}

Low back pain (LBP) is the most common orthopedic problem worldwide and is known to affect both younger and older adults (Strine and Hootman 2007; Shiri et al, 2008; Aggarwal et al, 2013). It has many consequences including disability and time off from work (Webb et al, 2003; Meerding et al, 2005). It is a major public health problem in the USA because more than 34 million (17\%) adults reported LBP only, and 19 million (9\%) reported LBP and neck pain in a 3 months duration (Strine and Hootman, 2007). Ayeni et al (2014) reported 59.7\% annual prevalence of lowback among craftsmen in Owerri, Nigeria. In the general population, the prevalence of low back pain in a 1-month and annual duration ranges from $30 \%$ to $40 \%$ and $25 \%$ to $60 \%$, respectively (McBeth and Jones 2007; Louw et al, 2007).

LBP is multi-factorial in nature, and researchers have focused on both clinical and nonclinical factors such as socio-demographic factors (Pincus, 2002; Mielenz et al, 2011; Nicholas, 2011). Positive association has been reported in some studies for age and LBP 
(Bener et al, 2003; Ouédraogo, 2010). Gender has also been identified as another predictor of LBP as the condition was found to be more common in female than in male (Hakala, 2002; Wijnhoven et al, 2006; McBeth and Jones, 2007; Shiri et al.2008; Schneider, Shiri, 2010). The sex difference could be related to gonadal steroid hormones such as estradiol and testosterone which modulate sensitivity to pain and analgesia (Craft et al, 2004). It was probable that LBP would have more influence on the life style habits in females than in males. Other variables such as diet, parity, and use of contraceptives may be relevant. Compared with unmarried, significantly increased odds of LBP were seen in married participants (Knox et al, 2011). There is the probability that the presence of a spouse may operate as a social factor on lack of LBP. It may include physiological mechanisms after their marriage.

Bener et al (2003) found a statistically significant association between place of residence and LBP among patients attending primary health care. Some studies have shown that smoking is consistently associated with LBP (Müller, 1999; Harreby 1996; Croft and Rigby 1994;). Findings from some studies showed that people with low levels of educational and low income have had the higher prevalence of LBP (Croft and Rigby, 1994; Müller 1999; Webb 2003).

Lowback pain still remains a major public health challenge. However until now, very few studies of the association between factors related to LBP have been carried out with focus on the sexual behaviour, with none available for citation amongst metal workers who are highly predisposed to experiencing lowback pain, especially in developing nations like Nigeria. Therefore, it is pertinent to determine the relationship between various factors of sexual behaviour/sexual pattern in relation to LBP. The primary aim of this study was to determine how sexual behaviour/characteristics enhance susceptibility to experiencing low back pain amongst metal workers in Owerri, Imo State. The objectives of the study are to determine distribution of metal workers according to gender; association between marital status and presence or not of sexual partner; association between marital status, sex frequency, number of sex partner and occurrence of lowback pain LBP among metal workers in Owerri, a southeastern Nigeria community.

\section{Materials and methods}

\section{Participants}

A case-control study was conducted into the population of metal workers (welders and panel beaters) in Owerri, South-east, Nigeria. Owerri is a city in South-Eastern Nigeria and is the capital of Imo State, set in the heart of the Igbo-land. Owerri consists of three Local Government Areas namely Owerri Municipal, Owerri North and Owerri West. It has a population of about 400,000 and is approximately 40 square miles $(100 \mathrm{~km} 2)$ in area. It is bordered by the Otamiri River to the east and the Nworie River to the south. It occupies the area lying between coordinates $5.484^{\circ} \mathrm{N}$ and $7.035^{\circ} \mathrm{E}$. Lowback pain case in this study is defined as pain or discomfort in the lowback area between twelfth rib and gluteal fold (lower $1 / 3$ of the back) with or without pain in one or both legs lasting one day or longer or strong enough to make the worker absent from work, in their life time. The control had no history of lowback pain that met the above definition. Participants with deformity, illness and obvious medical impairment were excluded from the study.

\section{Study design}

This study was a prospective case-control study design. A surveillance exercise was conducted during which cases and non-cases will be identified. A simple random sampling design was used to select 50 cases and 50 non-cases from identified cases and non-cases that met the inclusion criteria (i.e. 81 and 110 respectively). Frequency matching of cases and non-cases was carried out to minimize the effects of the co-founders. 


\section{Data collection and instruments for data collection}

After informed consent was sought and obtained from each worker, interviews using structured questionnaire was conducted with the help of trained field research assistants. The Questionnaire was prepared in English and it has three sections. Section A focused on sociodemographic information such as age, marital status, educational level etc. Section B sought answer to question on LBP history such as present and past lowback history and section $\mathrm{C}$ focussed on sexual habits such as sex frequency, number of sex partner of respondents. The questionnaire was assessed for content and face validity. It was also reviewed by two clinical researchers and two lecturers (one was an epidemiologist) who are knowledgeable in questionnaire design and development to ensure good face and content validity, with clear, unambiguous question. Test-retest reliability was equally carried out to ensure the questionnaire reliability. Informed consent was obtained from participants. Confidentiality of information was maintained throughout the study. This research was conducted in compliance with the Helsinki Declaration.

\section{Data analysis}

The data collected was manually sorted out, edited and coded. It was thereafter be imputed into the computer for analysis. Data will be analyzed using SPSS computer software version 17 (SPSS, Inc., Chicago, IL). Both descriptive statistics of mean, standard deviation, frequency and Inferential statistics of 2 X 2 contingency table was used for the data analysis. The level of significance will be set at $\alpha=0.05$.

\section{Results}

\section{Socio-demographic characteristics of respondents'}

A total of 100 metal workers (welders and panel beaters) were the respondents used for analysis. Cases were 50 and the remaining 50 were non-cases. They were samples randomly selected from the surveillance exercise cases and non-cases that met inclusion criteria (i.e. 81 and 110 respectively). The mean age of respondents was 35.19 years $(+/-8.976)$ with the youngest worker aged 19 years and the oldest aged 58 years. Of the respondents, $59 \%$ were welders while the remaining $41 \%$ were panel beaters. The mean duration of practice was found to be 8.25 years (+/-4.353). Presented in Table 1 is the summary the sociodemographic characteristics of the respondents. There was no variation in the gender distribution of metal workers; all metal workers are male.

\section{Relationship between marital status and presence of sexual partner}

From the study findings, $62 \%$ of the sampled population were married and thus had sex partners. The remaining 38\% were not married (single). However findings showed that they equally had sexual partners. All the sampled population of metal workers in Owerri had at least one sex partner. Hence, there was relationship between marital status and presence of sexual partner among the metal workers; this relationship is of sociological importance.

Table 1: Socio-demographic characteristics of panel beaters/welders

\begin{tabular}{llll}
\hline General characteristics & (variables) & Frequency $(\mathrm{n})$ & Percentage (\%) \\
\hline Age & $16-29$ & 5 & 5 \\
& $30-39$ & 42 & 42 \\
(Years) & $40-49$ & 44 & 44 \\
& $50-59$ & 9 & 9 \\
\hline Gender & Male & 100 & 100 \\
& Female & 0 & 0 \\
\hline Marital status & Single & 38 & 38 \\
& Married & 62 & 62 \\
\hline Metal Work & Panel beaters & 58 & 58
\end{tabular}


South American Journal of Public Health

Special Edition May 2016

\begin{tabular}{llll} 
Type & Welders & 42 & 42 \\
\hline Work & $0-5$ & 15 & 15 \\
Experience (Years) & 5 \& above & 85 & 85 \\
\hline Educational & Nil formal & 2 & 2 \\
Level & Primary & 1 & 1 \\
& Secondary & 96 & 96 \\
& Tertiary & 1 & 1 \\
\hline
\end{tabular}

\section{Relationship between Respondents' Sexual Habits and occurrence of LBP}

Presented in Table 2 is the distribution of characteristics of sexual habits of the metal workers in Owerri. Also presented in Table 3 is the relationship between lowback pain and various sexual habits. There was no association between identified sexual habits and lowback pain occurrence.

Table 2: Distribution of sexual characteristics of metal workers

\begin{tabular}{|l|l|l|l|}
\hline Habits (Variables) & Response & Frequency $(\mathrm{n})$ & Percentage \% \\
\hline Sex Partner & Yes & 100 & 100 \\
\hline & No & - & - \\
\hline No of sex partner & 1 & 87 & 87 \\
\hline & $>=2$ & 13 & 13 \\
\hline Sex frequency & $1-3$ & 90 & 90 \\
\hline & per week & $>4$ & 10 \\
\hline Married & Yes & 62 & 62 \\
\hline & No & 38 & 38 \\
\hline
\end{tabular}

Table 3: Odd ratios for LBP in relation to sexual habits of metal workers

\begin{tabular}{|l|l|l|l|l|l|}
\hline SBH Variables & & Total & LBP Proportion (\%) & Odd Ratio & 95\% CI \\
\hline Marital status & Single & 38 & 50.00 & 1.00 & \\
\hline & Married & 62 & 50.00 & 1.00 & $0.446-2.242$ \\
\hline Sex frequency & $1-3$ & 90 & 50.50 & 1.00 & \\
\hline /week & 4 \& above & 10 & 42.90 & 0.73 & $0.16-3.46$ \\
\hline Number of sex & 1 & 87 & 53.00 & 1.00 & \\
\hline partner(s) & 2 \& above & 13 & 23.10 & 0.26 & $0.061-16.44$ \\
\hline $\begin{array}{l}\text { SBH= sexual behaviour/habits } \\
\%=\text { percentage ; CI= confidence interval }\end{array}$ \\
\hline
\end{tabular}

\section{Discussion}

Back pain is a highly prevalent health problem worldwide. Its incidence and prevalence are so high that it should be studied as an epidemic and social disorder (Schmidt and Kohlmann, 2005). Ayeni et al (2014) found its point, annual and lifetime prevalence among craftsmen in Owerri including metal workers to be $34.0 \%, 57.4 \%$ and $69.0 \%$ respectively.

\section{Socio-demographic characteristics of the metal workers}

This study finding showed that majority of the population (86\%) that actively engaged as welders and panel beaters had their age ranged between 30 and 49 years. However, the mean age for the study was $36.29( \pm 8.98)$ years. On gender distribution, one important finding from this study is that all the metal workers were male (100\% male). Metal work is often seen as masculine or men dominated area of crafts work in this society. Meanwhile, Wheeler et al (2014) stated that risk factors for the back pain include older age, female gender, physically strenuous work, sedentary work, psychologically strenuous work, low educational attainment. 


\section{Relationship between marital status and presence of sexual partner(s)}

The study findings showed that all the sampled metal workers in Owerri had at least 1 sex partner irrespective of their marital status. This finding was highly remarkable, considering the high prevalence of sexually transmitted diseases in the society. To the best of my knowledge and available evidence, there is no data to compare this with as no previous studies have looked into this scenario among this population. It is important to explore further sexual behaviour of this population of workers with respect to prevalence of sexually transmitted diseases and determine to what extent they are informed or they take informed decision/action to protect themselves, their sexual partners and even their relations. There may be need for an advocacy programme on the prevention of sexually transmitted diseases to be carried out into this population, by the relevant public health agency in the state.

\section{Relationship between Sexual behaviour/habits and occurrence of LBP}

The findings of this study also showed that there were significant relationships between some identified habits and LBP. The finding of this study showed that no association was found between having more than one sex partner and occurrence of LBP $(\mathrm{OR}=0.26)$. Furthermore, no association was found between higher frequency of sexual bout/week and occurrence of lowback pain $(\mathrm{OR}=0.73)$. The general hypothesis is that engaging in frequent and /or uncontrolled sexual activities lead to occurrence of LBP. This finding of this study could not support the hypothesis. It was also established from this study that being married or not was not a significant risk factor to the occurrence of lowback pain

Compared with unmarried, Knox et al (2011) found significantly increased odds of LBP in married participants (Knox et al, 2011). It is possible that the presence of a spouse may operate as a social factor on lack of LBP. It may include physiological mechanisms after their marriage. According to Fillingim et al (2009), sex-related influences on pain and analgesia have become a topic of tremendous scientific and clinical interest, especially in the last 10 to 15 years. They concluded with a discussion on potential biopsychosocial mechanisms that may underlie sex differences in pain, and considerations for future research. Ambler et al (2001) in their study reported that there was a high prevalence of sexual difficulties in patients with chronic pain attending treatment. However, they did not specify how the sexual activities influence the occurrence of the pain. Horst (2015) in their study found that sexual activity and sexual function is an important consideration for patients with degenerative spine conditions and also showed that sexual function is a more relevant consideration for patients who are married, younger, and male. The second important finding of their study is that patients with degenerative conditions of the spine treated with surgery reported less pain with their sex-life compared to patients treated without surgery and there finding lasted throughout the four years of follow-up.

Limitation to the study includes limited time allotted for the surveillance. The inadequate controls (non-cases) from the metal workers population is also considered a limitation, though it was a reflection of high prevalence among the metal worker population. This could have paved way for a case - control matching process without variation in the matching age and year of experience (i.e. avoiding the $+/-3$ years age variation used for this study). Also, this study did not consider the impact of how long an individual has been engaging in each of the sexual factors/habits.

Further longitudinal study is equally recommended with more time allotted for surveillance exercise in other to get more number of cases and adequate controls and to enhance better matching process and also explore further the impact of duration and intensity of each identified habits with respect to occurrence of lowback pain.

\section{Conclusion}

The findings of this study showed no significant association was found between sex frequency, having sex partner or not, marital status and occurrence of lowback pain. It however identified the need for further study to determine how well metal workers manage 
South American Journal of Public Health

Special Edition May 2016

their sexual life and their health, as all sampled metal workers engage in sexual activities irrespective of their marital status.

\section{References}

[1.] .Aggarwal N, Anand T, Kishore J, Ingle GK. (2013): Low back pain and associated risk factors among undergraduate students of a medical college in Delhi. Educ Health (Abingdon); 26:103_8.

[2.] .Ambler N, de C W, Amanda C., Hill P, Gunary R, Cratchley GD. (2001): Sexual difficulties of Chronic Pain Patients. Clinical Journal of Pain; 17( 2): 138-145

[3.] .Ayeni GO, Morakinyo MO, Olaniyi O, Onigbinde AT, Ayeni OA (2014): Prevalence and Relationship between Analgesic and Alcohol Consumption, Smoking Habit and Occurrence of Lowback Pain amongst Craftsmen in a South-East Nigerian Community. American Journal of Health Research. Special Issue: Supplementary Prescribing in Nigeria: A Needy Concept to Promote Clinical Physiotherapy Practice; 2(1): 45-49.

[4.] .Bener A, Alwash R, Gaber T, and Lovasz G. (2003): Obesity and low back pain. Collegium Antropologicum, 27(1): 95-104.

[5.] .Craft RM., Mogil JS., and. Aloisi AM (2004): "Sex differences in pain and analgesia: the role of gonadal hormones," European Journal of Pain; 8(5):397-411.

[6.] .Croft PR and Rigby AS (19994): "Socioeconomic influences on back problems in the community in Britain," Journal of Epidemiology and Community Health, 48(2):166-170.

[7.] .Fillingim RB, King C.D, Ribeiro-Dasilva CM, Rahim-illiams B, Riley III JL (2009): Sex, Gender, and Pain: A Review of Recent Clinical and Experimental Findings . Journal of pain; 10 (5):447-485.

[8.] .Hakala P, Rimpelä A, Salminen J.J, Virtanen S.M, and Rimpelä M (2002): "Back, neck, and shoulder pain in Finnish adolescents: national cross sectional surveys," British Medical Journal: 325(7367):743-745.

[9.] .Harreby M, Kjer J, Hesselsøe G, and Neergaard K. (1986): "Epidemiological aspects and risk factors for low back pain in 38-year-old men and women: a 25-year prospective cohort study of 640 school children," European Spine Journal; 5(5): 312-318.

[10.] .Horst (2015): New research shows spinal surgery improves sexual function, reduces low back pain. American Academy of Orthopaedic Surgeons; March 24, 2015.

[11.] .Knox J, Orchowski J, Scher DL, Owens BD, Burks R, and Belmont PJ (2011): The incidence of low back pain in active duty United States military service members. Spine, 36(18):14921500 .

[12.] .Louw Q.A, Morris L.D, and Grimmer-Somers K (2007): The prevalence of low back pain in Africa: a systematic review. BMC Musculoskeletal Disorders; 8: 105.

[13.] .McBeth J and Jones K (2007): Epidemiology of chronic musculoskeletal pain. Best Practice and Research, 21(3):403-425.

[14.] .Meerding W.J, IJzelenberg W, Koopmanschap M.A, Severens J.L, and Burdorf A (2005): Health problems lead to considerable productivity loss at work among workers with high physical load jobs. Journal of Clinical Epidemiology, 58(5):517-523.

[15.] .Mielenz T.J, Devellis R.F, Battie M.C, and Carey T.S. (2011): Stop using the modified work APGAR to measure job satisfaction. Pain Research and Treatment, vol. 2011, Article ID 406235, 8 pp. [16.] .Müller C.F, Monrad T, Biering-Sørensen F, Darre E, Deis A, and Kryger P. (1999): The influence of previous low back trouble, general health, and working conditions on future sick-listing because of low back trouble: a 15-year follow-up study of risk indicators for selfreported sick-listing caused by low back trouble. Spine 24(15):1562-1570.

[17.] .Nicholas M.K, Linton S.J, Watson P.J, Main C.J., and Decade of the Flags Working Group (2011): Early identification and management of psychological risk factors ("yellow flags") in patients with low back pain: a reappraisal. Physical Therapy, 91(5):737-753.

[18.] .Ouédraogo D.D, Ouédraogo V, Ouédraogo L.T. et al (2010): Prevalence and factors associated with low back pain among hospital staff in Ouagadougou (Burkina Faso). Médecine Tropicale, 70(3):277-280. 
[19.] .Pincus T, Vlaeyen JW, Kendall NA, Von Korff MR, Kalauokalani D.A, and Reis S (2002): Cognitive-behavioral therapy and psychosocial factors in low back pain: directions for the future. Spine, 27(5):E133-E138.

[20.] .Schmidt CO and Kohlmann T. (2005): What do we know about the symptoms of back pain? pidemiological results on prevalence, incidence, progression and risk factors. Z Orthop Ihre Grenzgeb; 143: $292 \_8$.

[21.] .Schneider S, Randoll D, and Buchner M. (2006): Why do women have back pain more than men? A representative prevalence study in the Federal Republic of Germany. Clinical Journal of Pain, 22(8):738-747.

[22.] Shiri R, Karppinen J, Leino-Arjas P, Solovieva S, and Viikari-Juntura E. (2010): The association between obesity and low back pain: a meta-analysis. American Journal of Epidemiology, 171(2):135-154.

[23.] .Shiri R, Solovieva S, Husgafvel-Pursiainen K. et al (2008): The association between obesity and the prevalence of low back pain in young adults: the cardiovascular risk in young finns study. American Journal of Epidemiology, 167(9):1110-1119.

[24.] .Strine T. W. and Hootman J. M. (2007): US national prevalence and correlates of low back and neck pain among adults. Arthritis Care and Research, 57(4): 656-665.

[25.] .Webb R, Brammah T, Lunt M, Urwin M, Allison T, and Symmons D. (2003): Prevalence and predictors of intense, chronic, and disabling neck and back pain in the UK general population. Spine, 28(11):1195-1202.

[26.] .Wijnhoven H.A.H., de Vet H.C.W, and Picavet H.S.J. (2006): Prevalence of musculoskeletal disorders is systematically higher in women than in men. Clinical Journal of Pain, 22(8):717-724. 